\title{
Síndrome de Lemierre - A doença esquecida
}

\author{
Lemierre Syndrome - The forgotten disease \\ Carlos Eduardo Marcelloa, Elisabeth In Myung Kimª, \\ Luciana Andréa Avena Smeilia, Leonardo Bianquil ${ }^{b}$ Munir Bazzic
}

Marcello CE, Kim EIM, Smeili LAA, Bianqui L, Bazzi M. Síndrome de Lemierre - A doença esquecida. Autopsy Case Rep [Internet]. 2011;1(3):53-8. http://dx.doi.org/10.4322/acr.2011.009

\section{RESUMO}

As faringites agudas estão entre as causas mais comuns de procura aos serviços de emergência. De maneira geral, são doenças benignas, na sua grande maioria de etiologia viral ou bacteriana e cursam sem complicações quando instituída terapêutica apropriada. Raramente o processo infeccioso pode se estender para os planos profundos do pescoço e gerar complicações supurativas graves. Relatamos o caso de uma paciente de 20 anos que desenvolveu faringite aguda, logo seguida de abaulamento cervical à esquerda, além de tosse com laivos de sangue e infiltrados pulmonares bilaterais à radiografia do tórax - achado confirmado à tomografia de tórax que relevou parênquima pulmonar com nódulos cavitados medindo até $33 \mathrm{~mm}$ em lobos inferiores e superiores bilaterais, de localização periférica. A tomografia computadorizada do pescoço com contraste endovenoso mostrou trombose extensa da veia jugular interna esquerda, desde a base do crânio até o terço distal do pescoço Através dos procedimentos de imagem o diagnóstico de Síndrome de Lemierre foi feito e a paciente foi tratada com sucesso.

Unitermos: Síndrome de Lemierre; Faringite; Trombose venosa; Abscesso pulmonar.

\section{ABSTRACT}

Acute pharyngitis is among the most common causes of demand for emergency services. In general, they are benign, mostly of viral or bacterial etiology and evolve without complications with appropriate therapy. Rarely the infection extends deeply through the neck tissues generating serious suppurative complications. Herein is reported a case of a 20 -year-old young woman who developed acute pharyngitis followed by left cervical bulging and cough with bloody sputum. Chest radiography showed bilateral pulmonary infiltrate which on thoracic computed tomography slices were represented by cavitary nodules measuring up to $33 \mathrm{~mm}$ universally distributed on both lungs, predominantly on peripheral location. Computed tomography of the neck with intravenous contrast showed extensive thrombosis of the left internal jugular vein, from the base of the skull to the distal third of the neck. Diagnosis of Lemierre Syndrome was made and the patient was treated with a favorable outcome.

Keywords: Lemierre Syndrome; Pharyngitis; Venous thrombosis; Lung abscess.

\footnotetext{
a Divisão de Clínica Médica do Hospital Universitário - Universidade de São Paulo, São Paulo/SP - Brasil.

${ }^{\mathrm{b}}$ Faculdade de Medicina - Universidade de São Paulo, São Paulo/SP - Brasil.

${ }^{c}$ Instituto de Infectologia Emílio Ribas, São Paulo/SP - Brasil.
}

Copyright () 2011 Autopsy and Case Reports - Este artigo de Acesso Aberto é distribuído pelos termos do Creative Commons Attribution NonCommercial License (http://creativecommons.org/licenses/by/3.0/) que permite livre uso não-comercial, distribuição e reprodução em qualquer meio, desde que os artigos sejam devidamente citados. 


\section{RELATO DO CASO}

Paciente do sexo feminino, 20 anos, previamente hígida, procurou serviço de saúde com história de febre de $38{ }^{\circ} \mathrm{C}$ há 1 dia, odinofagia, mau hálito e discreto abaulamento cervical doloroso à esquerda. De antecedentes, a paciente referia apenas tratamento dentário incompleto em segundo molar superior esquerdo. $\mathrm{Na}$ ocasião, foi feito o diagnóstico de faringoamigdalite estreptocócica, tendo recebido Penicilina G Benzatina 2.400.000 U por via intramuscular, dose única. Evoluiu com persistência da febre e com surgimento de tosse com expectoração amarelada e laivos de sangue, associados a dor em hemitórax direito ventilatóriodependentee dispnéia. Retornouao mesmo serviçode saúde 3 dias depois, quando foi prescrita Amoxicilina com Ácido Clavulânico ( 875 mg/125 mg), duas vezes ao dia, por via oral. A paciente persistiu com o mesmo quadro clínico, tendo recebido, dias depois, um novo esquema antibiótico com Levofloxacina $500 \mathrm{mg}$ por dia, por mais 3 dias, sem melhora. Dez dias depois do início do quadro, procurou o Pronto Socorro do Hospital Universitário da Universidade de São Paulo com piora dos sintomas. Ao exame físico de entrada apresentava-se em regular estado geral, temperatura de $38,1^{\circ} \mathrm{C}$, descorada $1+/ 4+$, sudoréica, anictérica, acianótica, taquipnéica (frequência respiratória de 30 incursões por minuto), taquicárdica (frequência cardíaca de 108 batimentos por minuto); saturação arterial de oxigênio de $92 \%$ em ar ambiente. Ao exame da orofaringe apresentava hiperemia de tonsilas sem exsudato purulento.

À inspeção do pescoço notava-se discreto abaulamento em região cervical anterior esquerda, de consistência firme e com dor à palpação desde a região submandibular até a base do pescoço.

A propedêutica do coração, pulmões e abdome não apresentava alterações. na Tabela 1.

Os exames laboratoriais estão apresentados

A radiografia do tórax evidenciava opacidade em base pulmonar direita, sugestivo de processo broncopneumônico, bem como imagens cavitadas bilaterais com diâmetro de cerca de $2-3 \mathrm{~cm}$.

A paciente foi internada pela não resposta ao tratamento prévio e pelas imagens radiológicas, com hipótese diagnóstica de pneumonia da comunidade e linfadenite cervical à esquerda, sendo introduzida antibioticoterapia intravenosa com ceftriaxone $2 \mathrm{~g}$
Tabela 1 - Exames laboratoriais

\begin{tabular}{cccc}
\hline & & & VR \\
\hline Hemoglobina & $\mathrm{g} \cdot \mathrm{dL}^{-1}$ & 12,2 & $12,3-15,3$ \\
Hematócrito & $\%$ & 37 & $36,0-45,0$ \\
Leucócitos & $\mathrm{mm}^{3}$ & 14000 & $4,4-11,3.10^{3}$ \\
Bastonetes & $\%$ & 6 & \\
Segmantados & $\%$ & 77 & $46-75$ \\
Eosinófilos & $\%$ & 1 & $1-4$ \\
Basófilos & $\%$ & 1 & $0-2,5$ \\
Linfócitos & $\%$ & 14 & $18-40$ \\
Monócito & $\%$ & 1 & $2-9$ \\
Plaquetas & $\mathrm{mm}{ }^{3}$ & 193000 & $150-400.10^{3}$ \\
PCR & $\mathrm{ng} \cdot \mathrm{mL}^{-1}$ & 217 & $<5$ \\
Creatinina & $\mathrm{mg} \cdot \mathrm{dL}^{-1}$ & 0,9 & $0,4-1,3$ \\
Uréia & $\mathrm{mg} \cdot \mathrm{dL}^{-1}$ & 42 & $10-50$ \\
\hline
\end{tabular}

VR $=$ valor de referência.

dose única diária associada à claritromicina $500 \mathrm{mg}$ duas vezes ao dia. Foram realizadas três pesquisas de bacilo álcool-ácido resistente, pela coloração de Ziehl-Neelsen, todas negativas.

Para melhor caracterização do infiltrado pulmonar e das cavitações, evidenciados à radiografia simples, foi solicitada a tomografia computadorizada de tórax que mostrou parênquima pulmonar com nódulos cavitados medindo até $33 \mathrm{~mm}$ em lobos inferiores e superiores bilaterais, de localização periférica (Figura 1), que foram considerados como possíveis focos de embolização séptica. Essa possibilidade, a história prévia de faringite purulenta e o abaulamento cervical doloroso sugeriram o diagnóstico de síndrome de Lemierre, decorrente de infecção orofaríngea com extensão para espaços parafaríngeos causando trombose séptica de veia jugular interna com embolizações sépticas dirigidas para o coração direito e pulmões. Para confirmação, foi solicitada tomografia computadorizada do pescoço com contraste endovenoso, que mostrou trombose extensa da veia jugular interna esquerda, desde a base do crânio até o terço distal do pescoço (Figura 2). Após esta confirmação foi adicionada clindamicina $600 \mathrm{mg}$ de $6 / 6$ horas ao esquema terapêutico, com suspensão da claritromicina. A antibioticoterapia intravenosa foi mantida por 14 dias. A paciente evoluiu com melhora progressiva da febre e dos sintomas respiratórios, bem como do abaulamento em região cervical. No momento da alta estava assintomática e com programação de completar a antibioticoterapia de 6 semanas em caráter ambulatorial. 

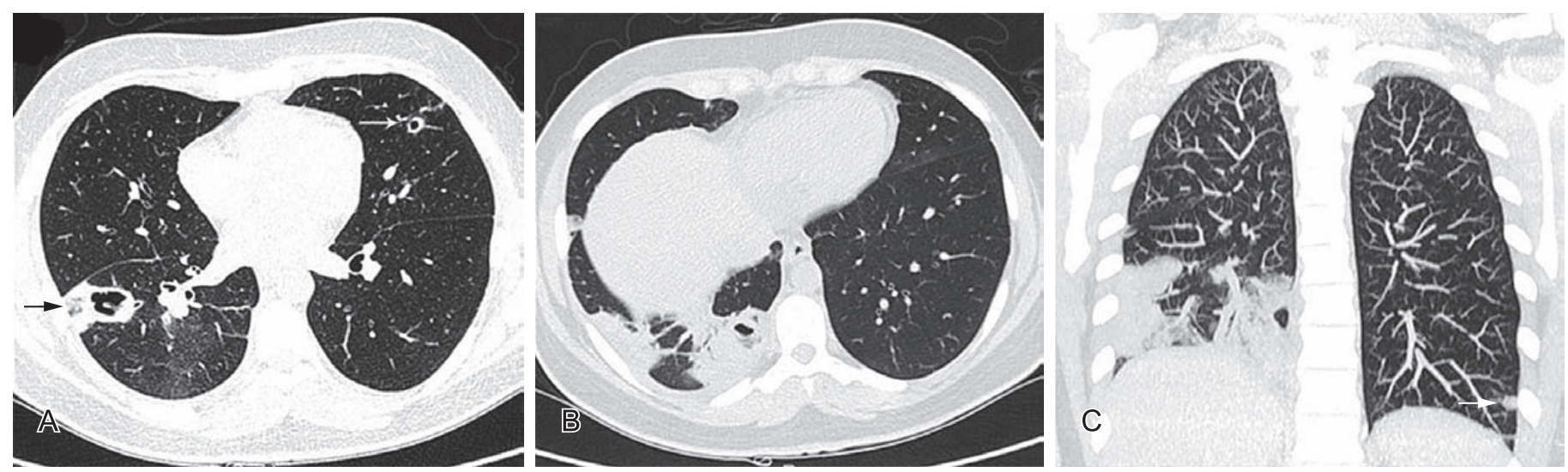

Figura 1 - Tomografia Computadorizada de Tórax. A - corte axial, janela pulmonar. Notar nódulos cavitados em região periférica do parênquima pulmonar, bilateral (setas); B - corte axial evidenciando áreas de consolidação com cavitação em lobo inferior direito; C - reconstrução coronal. Notar pequeno nódulo em lobo inferior esquerdo (seta), além das consolidações na base direita.
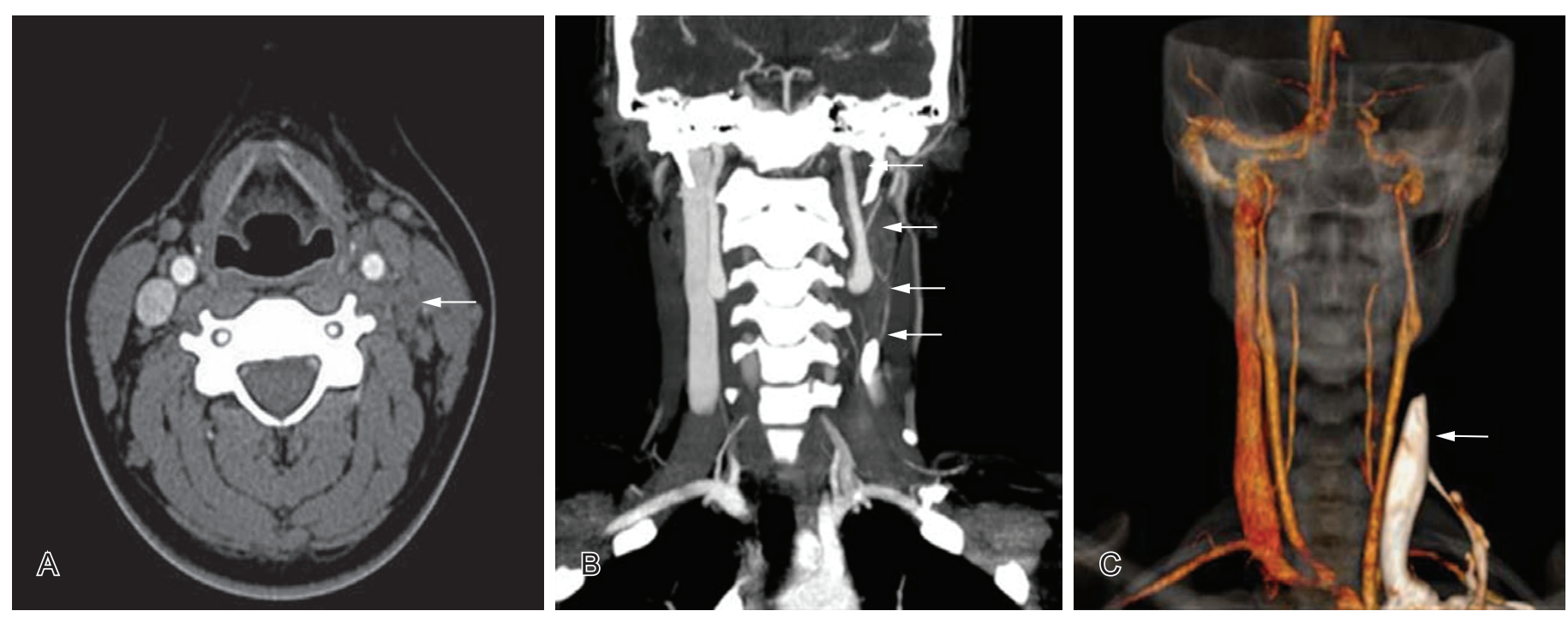

Figura 2 - Tomografia Computadorizada de Pescoço. A - corte axial após injeção de contraste endovenoso. Notar ausência de contrastação da veia jugular interna esquerda (seta); B - reconstrução coronal. A veia jugular interna esquerda não é visualizada (setas) desde a base do crânio até terço distal do pescoço, achado compatível com trombose extensa; C - reconstrução tridimensional. Notar contrastação retrógrada do terço proximal da veia jugular interna esquerda decorrente da injeção do meio de contraste no membro superior esquerdo (seta).

\section{DISCUSSÃO}

Em 1936, o microbiologista francês Dr. André Alfred Lemierre descreveu e publicou no The Lancet, a partir de 20 casos por ele observados, uma síndrome caracterizada por faringite causada por bactéria anaeróbia com acometimento de espaço faríngeo lateral incluindo uma tromboflebite de veia jugular interna que dá origem a infecções metastáticas especialmente para os pulmões, mas também para outros órgãos. ${ }^{1}$
Antes do aparecimento dos antibióticos a Síndrome de Lemierre era comum, mas passou a ser menos observada a partir dos anos 60 , talvez pelo uso disseminado de antimicrobianos para o tratamento de faringite. À época da descrição da doença, antes da disponibilidade dos antibióticos, a letalidade se aproximava de $90 \% .^{1,2} \mathrm{~A}$ partir dos anos 90 houve um reaparecimento de relatos e alguns atribuem esta mudança ao uso cada vez mais judicioso dos antibióticos. A familiaridade com os sinais e sintomas dessa síndrome diminuiu, em 
decorrência da incidência diminuída e, por isso, a síndrome passou a ser denominada como "a doença esquecida" ("the forgotten disease"). ${ }^{2}$

O agente etiológico mais comum da Síndrome de Lemierre é o Fusobacterium necrophorum, um comensal normalmente existente na cavidade oral, no trato genital feminino e no trato gastrointestinal. O F. necrophorum é um coco gram negativo anaeróbio encontrado como agente causal em cerca de $80 \%$ dos casos de síndrome de Lemierre. Outros microorganismos têm sido implicados isolada ou concomitantemente com o F. necrophorum na etiologia desta síndrome, como espécies de Bacteroides, estreptococos dos grupos B e C, Streptococcus oralis, Staphylococcus epidermidis, espécies de enterococos, Proteus mirabilis, espécies de Eubacterium, Eikenella corrodens, lactobacilos e espécies de Candida. As culturas são negativas em cerca de $10 \%$ dos casos. $^{3}$

O F. necrophorum, diferentemente de outras bactérias anaeróbias, tem uma capacidade incomum de causar doença grave em pessoas saudáveis com barreiras anatômicas intactas. A doença progride em diversas fases. O primeiro estágio é a infecção primária que geralmente se trata de faringite, mas que pode ser mastoidite ou infecção odontogênica. Esta é seguida de invasão local do espaço faríngeo lateral e de tromboflebite séptica da veia jugular interna e, finalmente, a ocorrência de complicações à distância. ${ }^{3}$

A maioria dos casos de Síndrome de Lemierre ocorre em adolescentes e adultos jovens.

Os pacientes apresentam faringite aguda, com febre em $82 \%$ das ocasiões, e, em menos de 1 semana, inicia-se a segunda fase, com dor eaumento de volume do pescoço, que são as manifestações do acometimento infeccioso do espaço faríngeo lateral, que conduzem ao envolvimento da veia jugular interna e desenvolvimento de trombose infecciosa.

Raramente, a artéria carótida pode ser acometida; Síndrome de Horner pode ocorrer se houver envolvimento do tronco simpático. ${ }^{3} \mathrm{~A}$ palpação da veia jugular interna trombosada é incomum.

O quadro clínico nessa fase caracterizase por dor e aumento de volume da face lateral do pescoço, podendo haver disfagia, presença de trismo, dor à movimentação do pescoço ou dor à palpação do músculo esternocleidomastoideo. É preciso ter em mente que os achados locais podem ser sutis ou ausentes, particularmente se a infecção predomina no compartimento posterior do espaço faríngeo lateral. $\mathrm{O}$ aumento do volume do pescoço ocorre em somente $50 \%$ dos casos. ${ }^{3}$

Quando um quadro de faringite aguda supostamente estreptocócica não apresenta remissão, deve-se considerar a possibilidade de condições clínicas como mononucleose infecciosa, complicação supurativa como linfadenite cervical ou a presença de um abscesso peritonsilar ou retrofaríngeo. Sintomas sugestivos de infecção faríngea profunda, como a que ocorre na Síndrome de Lemierre, incluem dor cervical, diminuição da mobilidade da mandíbula, do pescoço ou da língua ou trismo. ${ }^{3}$

A terceira fase se caracteriza por bacteremia com disseminação hematogênica para outros locais. Podem ocorrer infecções à distância em diversos órgãos. Os pulmões são os órgãos mais acometidos $(79,8 \%)$ seguidos das articulações $(16 \%)$. Há descrição de diversas possíveis manifestações de infecção à distância como (i) artrite séptica afetando úmero, quadril, clavícula tíbia e fíbula (em 16\%); (ii) manifestações intracranianas, incluindo meningite, abscessos epidurais/subdurais, trombose de seios venosos e acidente vascular cerebral; (iii) manifestações intratorácicas incluindo mediastinite, embolia pulmonar, empiema, hidropneumotórax e pneumonia (cavitações são descritas em cerca de $30 \%$ dos casos, sendo a metade visível somente à tomografia computadorizada do tórax), radiografias normais ocorrem em 12\%; manifestações oculares como uveite, hemorragia vítrea, massa retrobulbar e paralisia do $\mathrm{VI}$ par craniano; manifestações em fígado e baço, incluindo infartos e abscessos; (iv) manifestações renais como infartos e abscessos e (v) paralisia de nervos cranianos inferiores como as dos XI e XII pares. ${ }^{4}$ Em decorrência da septicemia o paciente pode apresentar também coagulação intravascular disseminada com trombocitopenia.

Faringite acompanhada de dor ou aumento do volume do pescoço deve ser avaliada com meticulosidade. É importante que se faça a coleta de hemoculturas e a administração precoce de metronidazol ou clindamicina. Deve-se procurar diagnosticar o estado da veia jugular do lado 
acometido com ultrassonografia, tomografia computadorizada ou ressonância magnética. Estudo radiológico do tórax deve ser feito se houver manifestações respiratórias, como tosse, expectoração ou dispnéia. Eventualmente, poderão ser encontrados infiltrados pulmonares ou cavitações sugestivas de abscessos, como nesta paciente ou, ainda, a presença de derrame pleural que deve ser investigado no que concerne à sua natureza - transudato ou exsudato (neste último caso, eventualmente pode ser necessária drenagem do tórax). Outras investigações de imagem podem ser necessárias na dependência de sintomas que possam sugerir o acometimento de outros órgãos. O papel da anticoagulação na Síndrome de Lemierre é controverso. ${ }^{3}$ Finalmente, em pacientes com sepse incontrolável e com evidências de embolias sépticas de repetição pode ser necessária a ligadura ou excisão da veia jugular acometida. Necessidade deste procedimento é rara na atualidade. A duração total da antibioticoterapia deve ser de 4 a 6 semanas.

Dados recentes sugerem que em adolescentes e adultos jovens (pessoas de 15 a 24 anos), o Fusobacterium necrophorum tem causado faringite endêmica numa frequência semelhante à dos estreptococos beta-hemolítico do grupo A. As estimativas sugerem também que o risco de Síndrome de Lemierre, uma doença potencialmente fatal, excede em muito o risco de febre reumática depois de uma faringite por estreptococo beta-hemolítico do grupo A. Daí a grande importância em se ter em conta a possibilidade de uma infecção faríngea causada por esse microorganismo anaeróbio nessa população. ${ }^{5}$

Diretrizes e artigos de revisão recentes sobre faringite ${ }^{6,7}$ dão ênfase ao diagnóstico e tratamento da faringite causada pelos estreptococos beta-hemolíticos do grupo $A$, por causa da importância das complicações supurativas e das não supurativas, como a febre reumática. Entretanto, recentes evidências ${ }^{8,9}$ sugerem que o Fusobacterium necrophorum é tão frequente quanto o estreptococo como agente etiológico da faringite aguda e sua complicação - Síndrome de Lemierre - é mais provável numa faringite por Fusobacterium do que o risco de desenvolver febre reumática pós faringite estreptocócica, de tal forma que é possível dizer que de todas as complicações mais sérias de uma faringite em adolescentes ou adultos jovens, a Síndrome de Lemierre é a mais frequente e a mais grave. ${ }^{5}$

\section{REFERÊNCIAS}

1. Lemierre A. On certain septicemias due to anaerobic organisms. Lancet. 1936;1:701-3. http://dx.doi.org/10.1016/S0140-6736(00)57035-4

2. Bliss SJ, Flanders SA, Saint S. Clinical problem-solving: a pain in the neck. N Engl J Med. 2004;350:1037-42. PMid:14999116. http://dx.doi.org/10.1056/NEJMcps032253

3. Chirinos JA, Lichtstein DM, Garcia J, Tamariz LJ. The evolution of Lemierre Syndrome. Medicine. 2002;81:45865. PMid:12441902. http://dx.doi.org/10.1097/00005792200211000-00006

4. Papadopoulos D, Assimakopoulos A. Lemierre syndrome: no delay in management. Am J Emerg Med. 2010; 28:844e1-2.

5. Centor RM. Expand the pharyngitis paradigm for adolescents and young adults. Ann Intern Med. 2009;151:812-5. PMid:19949147.

6. Snow V, Mottur-Pilson C, Cooper RJ, Hoffman JR; American Academy of Family Physicians; American College of Physicians; American College of PhysiciansAmerican Society of Internal Medicine; Centers for Disease Control. Principles of appropriate antibiotic use for acute pharyngitis in adults. Ann Intern Med. 2001;134:506-8. PMid:11255529.

7. Bisno AL, Gerber MA, Gwaltney JM Jr, Kaplan EL, Schwartz RH; Infectious Diseases Society of America. Practice guidelines for the diagnosis and management of group A streptococcal pharyngitis. Infectious Diseases Society of America. Clin Infect Dis. 2002;35:113-25. PMid:12087516. http://dx.doi.org/10.1086/340949

8. Amess JA, O'Neill W, Giollariabhaigh CN, Dytrych JK. A sixmonth audit of the isolation of Fusobacterium necrophorum from patients with sore throat in a district general hospital. Br J Biomed Sci. 2007;64: 63-5. PMid:17633139.

9. Batty A, Wren MW. Prevalence of Fusobacterium necrophorum and other upper respiratory tract pathogens isolated from throat swabs. Br J Biomed Sci. 2005;62:66-70. PMid:15997879. 
Conflito de interesse: Não há.

Submetido em: 28 de Julho de 2011

Aceito em: 14 de Agosto de 2011

Correspondência: Divisão de Clínica Médica

Av. Prof. Lineu Prestes, 2565, Cidade Universitária - São Paulo/SP - Brasil

CEP: 05508-000 - Tel.: +55 (11) 3091-9200

E-mail: carlosmarcello@hu.usp.br 